\title{
Estudio critico
}

Eutropio

de Valencia

María Adelaida Andrés Sanz

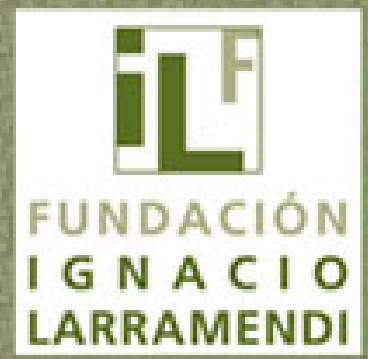

Biblioteca Virtual Ignacio Larramendi de Polígrafos 


\section{ESTUDIO CRÍTICO FHL}

(C) Del texto: el autor.

(C) De la edición: Fundación Ignacio Larramendi.

Madrid, 2011.

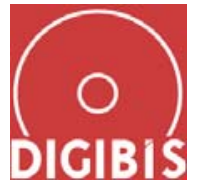

Es una edición electrónica de DIGIBÍS. 


\section{ESCRITORES VISIGÓTICOS}

\section{SIGLO VI}

\section{EUTROPIO DE VALENCIA}

MARÍA AdELAIDA ANDRÉS SANZ

Profesora titular en la Universidad de Salamanca

La vida y obra de Eutropio de Valencia se ve indisolublemente ligada a la de la historia política de la Hispania visigótica de su momento. Aunque sabemos más bien poco, lo que conocemos nos basta para hacernos una idea cabal de la importancia que su figura tuvo entre sus contemporáneos.

Como en otros casos, es Isidoro de Sevilla en su De uiris illustribus quien nos sirve de principal introductor a su vida y obra. A él se suma Juan de Biclaro, con algunas informaciones desgranadas en sus Chronica. Por ellos sabemos que fue abad del monasterio Servitano (fundado por el africano Donato hacia 567 en las proximidades de Cuenca, en la diócesis de Arcávica), desde donde luego fue promovido a la sede episcopal de Valencia, en la provincia Cartaginense, y que desde ambos puestos desempeñó un papel destacado entre los principales de su tiempo, especialmente en lo que hace a su trato con los monarcas visigodos Leovigildo y Recaredo. Aunque ni Isidoro ni Juan de Biclaro dan noticias acerca del origen de Eutropio, su posterior misión episcopal hace de él -como también de su corresponsal Liciniano de Cartagenapresumiblemente un hispano, habida cuenta de lo decretado en los cánones de Nicea, por los que en esta época se regían los nombramientos en Hispania. Aun así, hay quien postula que fue quizá uno de los monjes llegados de África con Donato. En cualquier caso, en 584 estaba al frente del monasterio servitano, y, según narra Juan de Biclaro, era ya famoso. Entonces se opuso con dureza a la persecución católica emprendida por el arriano Leovigildo -quien bien pudo haberlo conocido personalmente, dado que su Recópolis, de reciente fundación, se hallaba en la diócesis de Arcávica-, y su oposición se vio recompensada con el respeto del monarca.

En 589, a los tres años de la subida al trono y la conversión de Recaredo, se convoca el III Concilio de Toledo. Leandro, arzobispo de Sevilla, y Eutropio, abad del Servitano, son quienes, como sabios y respetados hombres de Iglesia, llevan las riendas de la preparación del encuentro. Poco después Eutropio fue nombrado obispo de Valencia, sede al frente de la cual debió de estar unos diez años, entre 590 y 600 . Son éstas unas fechas meramente estimativas: en 589 aún era abad, como hemos visto, y en 610 el 
obispo de Valencia, Martino, parecía llevar varios años asentado en tal sede. De ambos hechos se deduce que el episcopado de Eutropio debió de iniciarse tras el 589 y haber finalizado -con su muerte- en torno al 600.

La obra literaria que de Eutropio conservamos se reduce a dos cartas. No obstante, sabemos por Isidoro que su correspondencia fue ingente. Sabemos también que copias de la misma circularon, junto con cartas de Liciniano de Cartagena, por los más importantes monasterios europeos en la Edad Media, tal y como lo atestigua un catálogo de Cluny del s. XII, en el que se consignan "et mutue epistole Eutropii abbatis et Licinii (sic) episcopi Carthaginensis". Isidoro nos dice que era famosa una carta que dirigió precisamente a Liciniano a propósito de los ritos bautismales, y que éste le escribió otras muchas. En cualquier caso, por la noticia del catálogo de Cluny, y por la información de Isidoro, Díaz ha conjeturado que posiblemente los epistolarios de Eutropio y Liciniano circularon unidos, como una especie de corpus. Otro de sus corresponsales más frecuentes debió de ser el obispo Pedro de Arcávica, a quien escribiría desde su monasterio, antes, por tanto, de ser él mismo obispo. Precisamente, las únicas dos cartas que conservamos están dirigidas Pedro.

La Epistula ad Petrum de districtione monachorum es el primer testimonio literario eutropiano conservado, generalmente conocido como De districtione monachorum (Sobre el rigor que han de observar los monjes). Se trata de una carta en la que Eutropio se defiende ante su superior de las acusaciones que debieron de lanzar contra él varios monjes que, disgustados con la dirección de su abad, abandonaron el monasterio. Pudo haber sido escrita en torno al 580.

La segunda carta, De octo uitiis (Sobre los ocho vicios) es, en palabras de Díaz, “fundamentalmente un centón de Casiano". En ella glosa extensamente la Collatio V.

\section{BIBLIOGRAFÍA}

\section{Biografía}

- Domínguez del VAL, U., Historia de la antigua literatura latina hispano-cristiana, vol. 2, Madrid, Fundación Universitaria Española,1997, pp. 361-370.

\section{Ediciones}

a) De districtione monachorum (CPL 1096)

- DÍAZ Y DÍAZ, M. C., "Eutropii abbatis epistola de districtione monachorum ad Petrum papam", Anecdota wisigothica I. Estudios y ediciones de textos literarios 
menores de época visigoda, Salamanca, Universidad de Salamanca, 1958, pp. 20-26.

b) De octo uitiis (CPL 1095)

- DÍAZ Y DÍAZ, M. C., "Eutropii abbatis epistola de octo uitiis ad Petrum papam", Anecdota wisigothica I. Estudios y ediciones de textos literarios menores de época visigoda, Salamanca, Universidad de Salamanca, 1958, pp. 27-35.

\section{Otros estudios}

- DíAz y DíAz, M. C., "La producción literaria de Eutropio de Valencia”, Anecdota wisigothica I. Estudios y ediciones de textos literarios menores de época visigoda, Salamanca, Universidad de Salamanca, 1958, pp. 9-35.

-, "La vie monastique d'après les écrivains wisigothiques (VII ${ }^{\mathrm{e}}$ siècle)", Théologie de la vie monastique. Études sur la tradition patristique, Paris, Aubier, 1961, pp. 371-383 (reimp. id., Vie chrétienne et culture dans l'Espagne du VII $^{\mathrm{e}}$ au X ${ }^{\mathrm{e}}$ siècles, Aldershot, Variorum Reprints, 1992, $\mathrm{n}^{\mathrm{o}}$ VIII).

- Domínguez Del VAL, U.,"Eutropio de Valencia y sus fuentes de información”, Revista Española de Teología 14, 1954, pp. 369-392.

- , Estudios sobre literatura latina hispano-cristiana I: 1955-1971, Madrid, Fundación Universitaria Española, 1986, pp. 231-233.

- , Historia de la antigua literatura latina hispano-cristiana, vol. 2, Madrid, Fundación Universitaria Española, 1997, pp. 361-370.

- Gams, P. B., Kirchengeschichte von Spanien, vol. 2,1, Regensburg, 1880, pp. 257259.

- García Moreno, L. A., Prosopografía del reino visigodo de Toledo, Salamanca, Universidad de Salamanca, 1974, p. 147 (nº 366).

- Linage Conde, A., "El ideal monástico de los padres visigóticos”, Ligarzas 1, 1968, pp. 79-97.

- , "Eutropio de Valencia y el monacato", Salmanticensis 19, 1972, pp. 635-646.

- ReIfferscheID, A., Bibliotheca Patrum Latinorum Italica, vol. 1, Wien, 1870, p. 550.

- Robles Sierra, A., "Eutropio de Valencia, su figura y su doctrina", Teología Espiritual 21, 1977, pp. 301-322. 